\title{
Descripción del esqueleto axial del carpincho (Hydrochoerus hydrochaeris)
}

\author{
Bode, F.F.; Fernández, J.A.; Cao, J.A.; Resoagli, J.M. \\ Cátedra de Anatomía I, Facultad de Ciencias Veterinarias, UNNE, Sargento Cabral 2139, \\ Corrientes (3400), Argentina. Tel. 379-4425753, E-mail: anato@vet.unne.edu.ar.
}

\begin{abstract}
Resumen
Bode, F.F.; Fernández, J.A.; Cao, J.A.; Resoagli, J.M.: Descripción del esqueleto axial del carpincho (Hydrochoerus hydrochaeris). Rev. vet. 24: 1, 44-46, 2013. El "carpincho" es un roedor de gran talla ampliamente distribuido en la zona de llanos y humedales de Sudamérica. La información anatómica sobre el esqueleto axial de esta especie es escasa. El objetivo del ensayo fue describir el esqueleto axial de Hydrochoerus hydrochaeris. Se utilizaron tres cadáveres (dos machos y una hembra). Los huesos se obtuvieron por maceración, siendo luego tratados con hipoclorito de sodio al $20 \%$. Las descripciones anatómicas se avalaron con registros fotográficos. Se halló un total de 34 huesos de la cabeza (incluidos los huesos del oído y considerando el cornete nasal dorsal como parte del hueso etmoides), 36 vértebras (7 cervicales, 13 torácicas, 6 lumbares, 4 sacras y 6 caudales), 26 costillas, y el esternón con 6 esternebras. Osteológicamente los huesos de la cara resultaron más fuertes que los del cráneo. Se espera que los estudios anatómicos de H. hydrochaeris contribuyan a mejorar su manejo sanitario y productivo.
\end{abstract}

Palabras clave: Hydrochoerus hydrochaeris, anatomía, esqueleto, vértebras, cráneo.

\begin{abstract}
Bode, F.F.; Fernández, J.A.; Cao, J.A.; Resoagli, J.M.: Description of the axial skeleton of capybara (Hydrochoerus hydrochaeris). Rev. vet. 24: 1, 44-46, 2013. "Capybara" is a great size rodent broadly distributed in the areas of plains and swamps of South America. The anatomical information on the axial skeleton of this species is scarce. The objective of the assay was to describe the axial skeleton of Hydrochoerus hydrochaeris. Three cadavers were used (two males and one female). Bones were obtained by maceration, and later treatment with $20 \%$ sodium hypochlorite. Anatomical characteristics were photographically registered. Thirty four bones of the head (included ear bones and considering the dorsal nasal turbinates as part of the ethmoid bone), 36 vertebrae ( 7 cervical, 13 thoracic, 6 lumbar, 4 sacral and 6 caudal), 26 ribs, and the sternum with 6 sternebrae, were observed. From the osteological point of view, the bones of the face were stronger than those of the skull. It is expected that these anatomical findings in $H$. hydrochaeris may contribute to improve the sanitary and productive handling of the species.
\end{abstract}

Key words: Hydrochoerus hydrochaeris, anatomy, skeleton, vertebras, skull.

\section{INTRODUCCIÓN}

La fauna silvestre ha sido fuente alimentaria, artesanal, comercial y medicinal para la población rural del nordeste argentino. Una de las especies autóctonas de la zona es el "capincho" (Hydrochoerus hydrochaeris), también conocido con los apelativos "capibara" y "chigüire", roedor ampliamente distribuido en Sudamérica ${ }^{5}$.

La importancia económica de este animal está evidenciada por los numerosos programas de explotación nacionales y regionales, la mayoría de ellos congruentes en que el usufructo del recurso fáunico debe de-

Recibido: 21 marzo 2013 / Aceptado: 13 mayo 2013 sarrollarse a la par de investigaciones científicas que mejoren las condiciones de crianza, el manejo sanitario y la conservación de la especie ${ }^{1}$.

En roedores silvestres de gran talla, la información anatómica y/o radiográfica sobre el esqueleto axial es escasa o inexistente. En H. hydrochaeris se han realizado estudios sobre la anatomía del tórax ${ }^{3} \mathrm{y}$ en Agouti paca ("agutî") se hallaron resultados de investigaciones sobre esqueleto apendicular ${ }^{4}$ y esqueleto axial ${ }^{6}$. La ausencia de datos anatómicos entorpece la interpretación de exámenes clínicos tornando difícil la descripción de afecciones que involucren piezas óseas.

El esqueleto axial de los mamíferos comprende la columna vertebral, las costillas, el esternón y la calave- 
ra $^{2}$. Avizorando que en H. hydrochaeris el estudio de las estructuras anatómicas en general y osteológicas en particular contribuirán a la profundización de su cuidado sanitario y a la optimización del manejo zootécnico y productivo, el objetivo de este trabajo fue describir anatómicamente las estructuras de su esqueleto axial.

\section{MATERIAL Y MÉTODOS}

Se utilizaron tres cadáveres de ejemplares adultos de H. hydrochaeris (dos machos y una hembra), decomisados por la Dirección de Flora y Fauna de la Provincia de Corrientes y donados a cátedra de Anatomía en la cual se realizaron los estudios. Los procedimientos utilizados fueron el desuello, eviscerado, macerado y secado. Los huesos fueron tratados con hipoclorito de sodio al $20 \%$. Los hallazgos fueron registrados fotográficamente.

\section{RESULTADOS Y DISCUSIÓN}

El número de piezas óseas identificadas en el esqueleto axial de $H$. hydrochaeris, agrupadas por zona topográfica fueron: 34 huesos de la cabeza (incluidos los huesos del oído, considerando el cornete nasal dorsal parte del hueso etmoides), 36 vértebras, 26 costillas y el esternón con 6 esternebras. Para su descripción, la cabeza se dividió en rostro y cráneo. El rostro estuvo conformado por huesos pares e impares. Los pares fueron: incisivo,

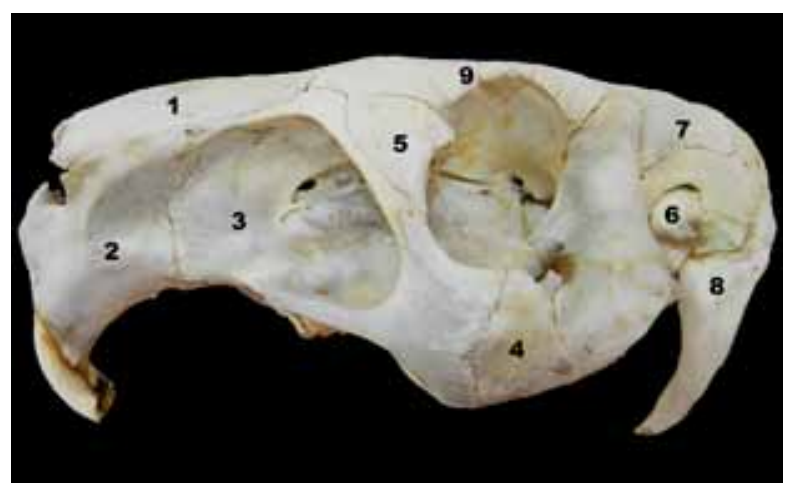

Figura 1. Huesos: nasal (1), incisivo (2), maxilar (3), yugal (4), lagrimal (5), temporal (6), parietal (7), occipital (8), frontal (9).

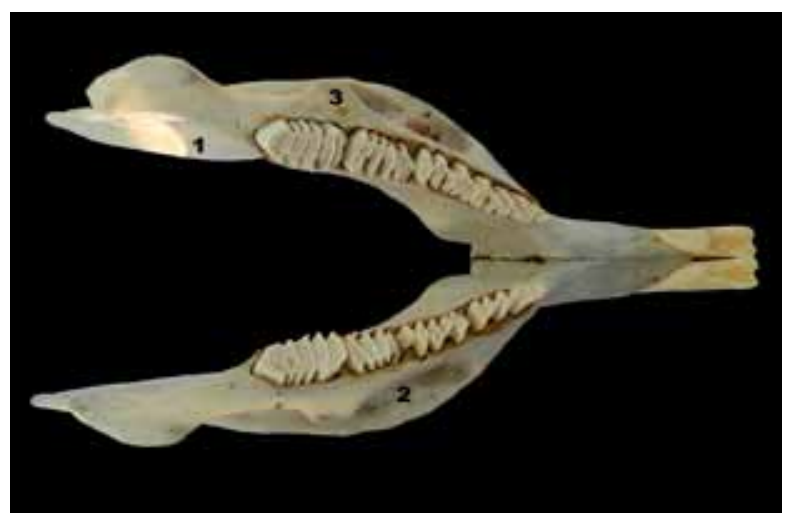

Figura 2. Mandíbula: cóndilo (1), fosa muscular (2), apófisis coronoidea (3). nasal, maxilar, lagrimal, yugal (Figura 1), palatino, pterigoides y cornete nasal ventral. Los impares fueron: vómer, hioides y mandíbula. En el cráneo los huesos pares fueron: frontal, parietal y temporal, en tanto que los impares fueron: occipital, esfenoides y etmoides.

Los huesos incisivos presentaron un cuerpo estrecho, alargado y sólido, el borde alveolar estuvo ocupado totalmente por la cavidad alveolar, donde se implantaron los dos dientes incisivos. La apófisis nasal, larga y dirigida caudalmente, se unió en dorsal con el hueso nasal, en ventral con el hueso maxilar y en caudal con el hueso frontal. Rostral y dorsalmente se observó una apófisis prominente, elevada y aguzada que recordó al hueso rostral del cerdo ${ }^{2}$.

Los huesos nasales fueron espesos, relativamente largos, anchos, convexos externamente, de forma rectangular, cuyo borde lateral se unió a la apófisis nasal del incisivo. En el borde rostral se observó una incisura que delimitó dorsal y lateralmente la entrada de la cavidad nasal. Los huesos maxilares, bien desarrollados, mostraron una cara lateral excavada, cuyo extremo caudal formó el piso de la órbita. La apófisis cigomática se fusionó con la frontal y se unió al hueso yugal, delimitando el foramen infraorbitario. El borde ventral presentó cuatro alvéolos para los molares.

Los huesos lagrimales revelaron forma piramidal, cuya base delimitó cranealmente la órbita; en lateral se destacó una eminencia ósea donde se insertó un cordón fibroso. El hueso yugal formó la parte media del

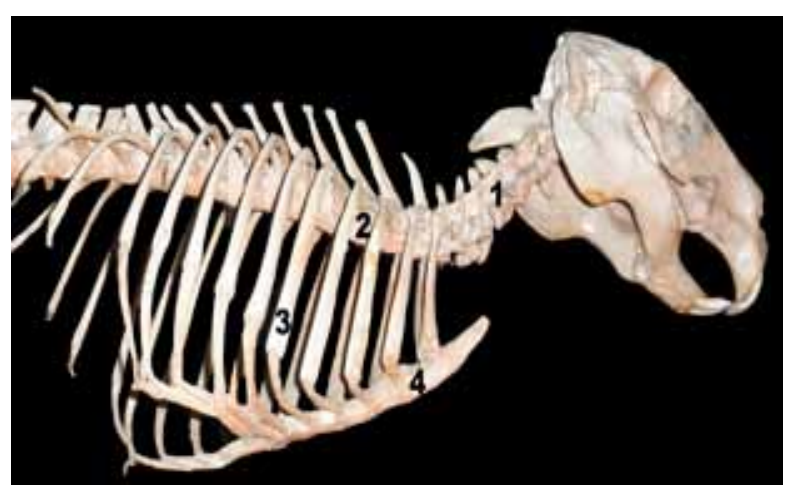

Figura 3. Vértebras cervicales (1), vértebras torácicas (2), costillas (3), esternón (4).

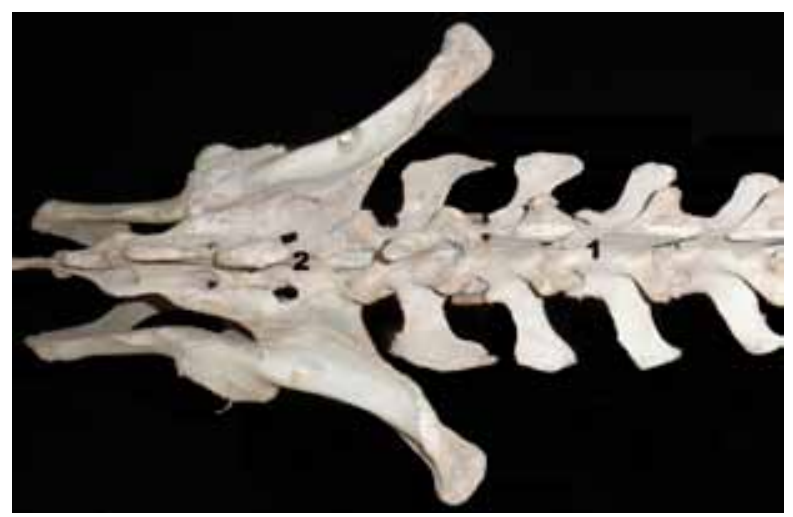

Figura 4. Vértebras lumbares (1) y sacras (2). 
arco cigomático, se unió cranealmente con el maxilar y caudodorsolateralmente con la apófisis cigomática del temporal. El hueso palatino mostró forma triangular, integrando parte del techo de la cavidad bucal. En la mandíbula se distinguieron la apófisis angular, bien desarrollada, y los cóndilos longitudinales. Lateralmente, una cresta y una fosa bien destacadas constituían el punto de inserción del músculo masetero. En la elevada apófisis coronoidea se fijó el músculo temporal (Figura 2).

En el cráneo, los huesos temporales (Figura 1) se destacaron por la apófisis cigomática, que unida al hueso yugal formaron la cavidad glenoidea longitudinal, para el cóndilo mandibular. Los frontales formaron parte de las cavidades nasal y craneana. El hueso occipital se caracterizó por presentar el agujero magno de forma triangular y las apófisis yugulares bien desarrolladas, así como ausencia del interparietal. Como en el resto de los mamíferos la columna vertebral estuvo formada por 5 regiones bien diferenciadas, el número de vértebras fue constante en los ejemplares estudiados: 7 vértebras cervicales, 13 torácicas, 6 lumbares, 4 sacras y 6 caudales, presentando diversas particularidades en las distintas regiones (Figuras 3 y 4 ).

Todas las vértebras cervicales presentaron agujero transverso y apófisis espinosas. El atlas mostró mayor desarrollo del tubérculo dorsal, así como horizontalidad de las alas y presencia del agujero transverso que comunicaba con el canal vertebral. En el axis la cresta dorsal, muy desarrollada, se proyectó caudalmente sobre la $\mathrm{II}^{\mathrm{a}}, \mathrm{III}^{\mathrm{a}}$ y IV $\mathrm{IV}^{\mathrm{a}}$ vértebras cervicales. En las vértebras torácicas las apófisis espinosas aumentaron de tamaño desde la $\mathrm{I}^{\mathrm{a}}$ a la $\mathrm{IV}^{\mathrm{a}}$, disminuyendo luego hasta la XIII ${ }^{\mathrm{a}}$, con caudoversión desde la $\mathrm{I}^{\mathrm{a}}$ a la XI ${ }^{\mathrm{a}}$. En la $\mathrm{XII}^{\mathrm{a}}$ fue vertical y en la XIII ${ }^{\mathrm{a}}$ se inclinó cranealmente. En las vértebras lumbares, las apófisis espinosas se mostraron anchas en su borde libre y estrechas en la base, con craneoversión y presencia de apófisis mamilares. Las apófisis transversas sufrieron craneoversión, aumentando el tamaño desde la I a la última; en la base del borde caudal ostentaron una apófisis accesoria dirigida hacia caudal que disminuyó de tamaño gradualmente, para desaparecer en la última vértebra.

El sacro se formó por la fusión de cuatro vértebras; su cara ventral fue cóncava en ambos sentidos, con tres agujeros ventrales. Las apófisis espinosas eran tuberosas, dirigidas caudalmente y no se fusionaron entre sí. Sobre la cara dorsal de la primera se evidenciaron las apófisis mamilares. Las apófisis transversas de las dos primeras vértebras se fusionaron conformando las alas del sacro, las cuales articularon con el coxal. Las dos primeras vértebras caudales mantuvieron la característica de la vértebra tipo, sin apófisis transversa. Las láminas del arco de las vértebras III ${ }^{\mathrm{a}}$ I IV ${ }^{\mathrm{a}}$ no se fusionaron, y las dos últimas se redujeron a un cuerpo cilíndrico. La longitud y el diámetro disminuyeron desde la Ia a la última.

Se registraron 13 pares de costillas; 7 esternales y 6 asternales. Las 5 primeras eran aplanadas lateralmente y se ensanchaban hacia el extremo ventral. A partir de la $\mathrm{VI}^{\mathrm{a}}$ se tornaban cilíndricas gradualmente, aumentan- do su longitud y curvatura desde la $\mathrm{I}^{\mathrm{a}}$ a la VII ${ }^{\mathrm{a}}$; luego disminuían progresivamente hacia la última (Figura 3). En el tercio proximal del borde caudal de la III a la $\mathrm{VI}^{\mathrm{a}}$ se observó una tuberosidad bien destacada, que disminuyó en la VII ${ }^{\mathrm{a}}$ y VIII ${ }^{\mathrm{a}}$ desapareciendo en las cinco últimas. El esternón estuvo formado por 6 esternebras; la I ${ }^{a}$ reveló una longitud mayor a las demás (Figura 3).

Las vértebras presentaron características que permitieron diferenciar las 5 regiones descriptas para los mamíferos domésticos en los tratados clásicos de anatomía $^{2}$. En las cervicales se mantuvo el número de 7 como en todos los mamíferos, destacándose una región caudal corta. El esternón resultó ser largo y estrecho, como en la mayoría de los roedores ${ }^{7}$, característica ostentada por la primer esternebra, al igual que los roedores que no poseen clavícula. La órbita y la fosa temporal fueron continuas, característica propia de los roedores ${ }^{7}$. El hueso yugal formó la parte media del arco zigomático, que unido al temporal delimitaron la cavidad glenoidea. Al igual que en otros roedores presentó una gran abertura que correspondió al foramen infraorbitario. El hueso nasal no alcanzó el extremo rostral.

En general, las observaciones efectuadas en el esqueleto axial de H. hydrochaeris responden a las descripciones publicadas para los roedores en general ${ }^{2,6,7}$, con algunas particularidades que lo diferencias de otras especies. Se espera que los datos consignados contribuyan al mejor conocimiento de la anatomía del "carpincho" y a una más correcta interpretación de sus patologías, tanto en ejemplares de vida libre como en establecimientos de cría.

\section{REFERENCIAS}

1. Bolkovic ML, Ramadori D. 2006. Manejo de fauna silvestre en Argentina. Programas de uso sustentable, $\mathrm{Pu}-$ blic. Secretaría de Ambiente y Desarrollo Sustentable, Buenos Aires, 168 p.

2. Getty R. 1982. Anatomía de los animales domésticos, $5^{\circ}$ ed., Interamericana, México, p. 1356-1375.

3. Mendoza TH. 1977. Tórax del chigüire (Hydrochoerus hydrochaeris hydrochaeris), cavidad, análisis y topografía de órganos y trayectos vasculo-nerviosos. Trabajo de Ascenso, Univ. Central Venezuela, $45 \mathrm{p}$.

4. Moreno V, Cardona J, Sánchez R, Acero D, Gordillo M. 2011. Descripción anatómica per se y particularidades osteológicas del esqueleto apendicular de Agouti paca. Rev CienciAgro (Journal de Ciencia y Tecnología Agraria, La Paz, Bolivia) 2: 279-290.

5. Ojasti J. 1973. Estudio biológico del chigüire o capiba$\mathrm{ra}$, Ed. Fondo Nacional de Investigaciones Agropecuarias, Caracas (Venezuela), p. 62-64.

6. Oliveira FS, Canola JC, Machado MR, Camargo MH. 2006. Descrição anatomo-radiológica do esqueleto axial da paca (Agouti paca, Linnaeus, 1766). Acta Scientiae Veterinariae 34: 331-334.

7. Parker J, Haswell W. 1987. Zoología - Cordados, $7^{\circ}$ ed., Reverté, Barcelona, p. 663-670. 